\title{
REBELIONES COLONIALES \\ Y GOBIERNO DE LAS INDIAS \\ EN LA SEGUNDA MITAD DEL SIGLO XVI
}

Gregorio Salinero

Université Paris 1 Panthéon-Sorbonne

\begin{abstract}
$\mathrm{F}^{\mathrm{l}}$ alcance de los movimientos de desobediencia que Eemergieron en las Indias durante la segunda mitad del siglo Xvi ha sido minimizado. La traición de Martín Cortés, Marqués del valle de Oaxaca e hijo legítimo de Hernán Cortés, es un ejemplo emblemático de este mecanismo. Tras siete años de proceso, la justicia real determinó su culpabilidad por un crimen de lesa majestad, pero hasta los mismos contemporáneos dudaron de que hubiera urdido un complot para eliminar a los oidores de México y proclamarse rey. La confluencia de factores históricos y políticos muestra este proceso de reducción memorística fundamentado por los cronistas fieles al partido realista. Las publicaciones de los americanistas pueden dar la impresión de que las rebeliones del ámbito colonial castellano fueron fomentadas exclusivamente por las poblaciones indígenas. Los trabajos orientados en este sentido han generado notables resulta-
\end{abstract}

Fecha de recepción: 11 de marzo de 2014

Fecha de aceptación: 15 de mayo de 2014 
dos. ${ }^{1}$ No obstante, más allá de limitarse a un careo entre pobladores e indios, las guerras del siglo XVI, con frecuencia enfrentan a los españoles que, a menudo, son respaldados por alianzas indias, un hecho que apenas ha suscitado trabajos entre los historiadores.

En su momento, Marcel Bataillon insistió en estos fenómenos, haciendo un llamamiento

[...] pour cette investigation [...] un réseau international de laboratoires ou d'ateliers. Une constellation de ceux-ci pourrait être consacrée à connaître à fond le mouvement pizarriste, ses antécédents, ses ramifications et ses répercussions au travers de l'Hispania des deux Mondes. ${ }^{2}$

Con uno de sus colaboradores, Robert Klein, Bataillon confeccionó un fichero de personajes implicados en estos acontecimientos sin obtener resultados concluyentes. Aunque quisiéramos hacerlo, sería imposible reducir la rebelión de los pobladores a una reacción efímera contra la publicación de las Leyes Nuevas de 1542, las cuales pretendían abolir la esclavitud de los indios y suprimir paulatinamente las encomiendas, los repartos de indios que la corona había encargado al cuidado de los conquistadores. Esta tutela obligaba a su titular a ocuparse de evangelizar a los indígenas, educarlos y garantizar su protección, compromiso que los primeros españoles habían transmitido a sus hijos;

${ }_{1}$ Duviols, La Lutte contre les religions autochtones du Pérou colonial; Powell, La guerra chichimeca; BARral Gómez, Rebeliones indígenas; Zavala, Les Indiens Mapuche du Chili; Giudicelli, Pour une géopolitique de la guerre des Tepehuán.

2 Bataillon, "Interés hispánico del movimiento pizarrista", pp. 47-56. 
por ello la generación encargada de las encomiendas durante la segunda mitad del siglo Xvi fue precisamente la de sus herederos. Los depositarios de esos repartos, los encomenderos, no eran ni propietarios de las tierras de sus pueblos ni detentadores de la jurisdicción de sus indios.

La encomienda no era un señorío. Dependía de la justicia real, que los corregidores y las audiencias garantizaban, pudiendo la corona recuperar su tutela efectiva. Salvo derogación particular, las encomiendas debían serle devueltas tras la primera transmisión de una de ellas, encomienda en segunda vida. A la inversa, los encomenderos que aspiraban a convertirse en auténticos señores, según la modalidad peninsular, reclamaban la perpetuidad de sus repartos y la jurisdicción personal sobre los indios. Desde hacía tiempo se había suspendido la aplicación de las Leyes Nuevas, cuando el inquisidor La Gasca, enviado a Perú como comisario del rey y del presidente de la Audiencia de Lima, prendió a Gonzalo Pizarro el 9 de abril de 1548 durante la batalla de Xaquixaguana. Lo cierto es que, desde el año 1545, Carlos V había retrocedido en la aplicación de las leyes para el sector de México, admitiendo la transmisión de las encomiendas en segunda vida. Aun así, su suspensión parcial no puso fin a los proyectos de insurrección, como tampoco sosegó el espíritu de desobediencia. Sin duda, en Perú, su réplica fue el detonante del movimiento insurreccional, el cual excedió rápidamente a la simple protesta contra las medidas de la política peninsular para tornarse en manifestación radical contra la autoridad del rey de Castilla. La mayoría de los insurgentes, de diferentes categorías, no pertenecían al bando de los encomenderos, antes bien muchos aspiraban a serlo, por lo que hicieron suya la propuesta. El interés de los más acomodados 
coincidía de ese modo con el de los españoles que carecían de indios, lo que supuso un acercamiento que constituyó la base de una unión particularmente peligrosa para la corona.

Debe añadirse a todo ello que los movimientos de desobediencia no asumieron la forma de simples revueltas nobiliarias o señoriales. Se asemejaban, a un tiempo, al motín fiscal - ya que la revisión del tributo solicitado a los indios suscitaba el descontento - y a la revuelta campesina - pues la organización de las acometidas militares se tramaba con frecuencia en los pueblos de las encomiendas donde los últimos emigrantes estaban al servicio de los pobladores más poderosos-. La corona podía argüir que los encomenderos y sus herederos formaban el grupo de los gratificados por la conquista cuando, en realidad, advertía perfectamente que el séquito de emigrantes pobres y soldados ociosos constituía el grueso de la tropa de los descontentos.

Los continuos virajes y la aparente indecisión de la corona en materia de reglamentación hacían que los pobladores estuvieran sujetos a una insoportable amenaza. Numerosas conjuras de las décadas de 1550 y 1560 se urdieron sobre rumores inciertos relativos a las medidas discordantes de la Península. Nos limitaremos aquí a hacer alusión a algunas de las rebeliones más señaladas. No faltaron tampoco las respuestas al estremecimiento, suscitadas por la insurrección de Pizarro, que duró de 1544 a 1548: las de Sebastián de Castilla, Egas de Guzmán y Hernández de Girón, que fracasaron en 1553 y 1554; las rebeliones de Rodrigo de Contreras y sus hijos en Nicaragua, Costa Rica y Panamá, cuyas persecuciones judiciales duraron hasta 1554; las sublevaciones en La Paz de Antonio Carrillo y Francisco Boloña, bajo la influencia de Hernández de Girón; el periplo de Lope de Aguirre y sus cómplices, 
perseguidos hasta 1561 por las tropas del rey, y el complot de Martín Cortés, iniciado en 1565. Se expandieron numerosos ecos lejanos de estos movimientos: el complot mestizo de los Maldonado en Huamanga, en 1567; la tentativa de rebelión de La Paz, dirigida en 1576 por un tal Alonso de Mena; o en 1583, en Quito, el movimiento del joven Miguel de Benalcázar. Eran rebeliones dentro de las rebeliones, y cada una de ellas se engranaba en persecuciones duraderas cuyos efectos se dejaban sentir hasta los pueblos de la Península, donde los descendientes de un rebelde podían ser perseguidos, a su vez, años después de que hubieran ocurrido los hechos.

A partir de entonces, el gobierno de las Indias se esforzaba en interrogar a cada sospechoso. Es cierto que la insurrección andina de Gonzalo Pizarro había movilizado como mínimo a 1500 españoles, y la de Francisco Hernández de Girón al menos a un millar de ellos. En cambio, a principios de la década de 1550, no eran más de 3000 a 4000 en el Perú colonial. El recuento de millares de procesos políticos de la segunda mitad del siglo xvi permite restituir a la América sediciosa el lugar que le corresponde. ${ }^{3}$

${ }^{3}$ Este texto apunta sólo a subrayar algunos aspectos tratados por SALINERo, La trabison de Cortés. Los procesos estudiados para estos trabajos se encuentran en las series Patronato y Justicia del Archivo General de Indias, en la serie Diversos de Indias del Archivo Histórico Nacional y, en parte, en el Archivo General de la Nación de México. Merecen un estudio de su continuidad, hasta el siglo xvir, y un intenso seguimiento del eco de estos asuntos en los archivos notariales. 
De la desobediencia pasiva hasta la insurrección armada, pasando por la simbólica, todas las formas de insumisión a la corona se calificaban de rebelión. Se consideraba que Perú era tierra de traidores, el país donde nadie querría morir en nombre del rey. Los primeros días de la acusación contra Martín Cortés, en julio de 1566, se reprochó al detenido haber constituido una coalición con el objeto de sublevarse contra las autoridades. El 18 de julio, los oidores establecieron las bases de la acusación del Marqués en un texto que le imputaba la organización activa de la revuelta, el trato de rebelión y levantamiento de Nueva España. La presunción se transformaba así en imputación argumentada. Más tarde, se trató de rebelión, de junta y de confederación, términos que resultaron más prudentes, aunque la palabra rebelión se mantuvo como la más extendida.

A la espera de una calificación jurídica precisa, bastaba con la perniciosa asociación para justificar la encarcelación del Marqués y sus cómplices. La primera acusación dejaba a un lado los dilatados esfuerzos de los juristas que habían comentado el Corpus Iuris Civilis, la gran compilación del derecho romano, distinguiendo la coniuratio de la conspiratio y de la machinatio. ${ }^{4}$ La mayoría podía entrar en la categoría de la proditio, el crimen de traición doble por una alianza con los enemigos del soberano. Habiendo sido descubierto antes de su conclusión, el complot de Cortés no se saldó con una insurrección armada (congregatio gentis armate). El

${ }^{4}$ SBriccoli, Crimen laesae maiestatis. 
Marqués había cometido nada menos que un atentado contra el servicio de Su Majestad (atentado al servicio de Su Majestad). Tan sólo los documentos puramente jurídicos pergeñados por el Consejo de Indias para asentar la culpabilidad de Martín Cortés determinaban el crimen de lesa maiestatis. Sin embargo, la acumulación de las formas de desobediencia a la corona registradas contra el Marqués induce a calificar su actitud de crimen gravísimo y atroz, que incurría en los castigos más rigurosos. Había ofendido a Su Majestad y contribuido a derrocar la república (ofendido a su real majestad y demolido contra la república). ${ }^{5}$

Durante los procesos, los jueces prestaron atención particular a las formas de desobediencia simbólica. El Marqués, secundado activamente por Alonso de Ávila, uno de sus jóvenes parientes encomenderos, fue condenado por haber querido eliminar a los oidores en ausencia de virrey, apoderarse de la casa real y haber pensado proclamarse rey del país. La coalición, urdida desde el otoño de 1565, había sufrido altibajos. Los delatores y otros testigos que lo instimularon coincidían en la implicación de Alonso de Ávila y su hermano Gil de Ávila. A lo largo de los testimonios, fue denunciado otro centenar de individuos, encomenderos y emigrantes pobres provenientes de la Península, Guatemala y Perú.

Con toda certeza, la casa del Marqués lideraba una vasta red de complicidad sediciosa que se extendía a toda la América española. Y lo que es más, la coalición estaba arraigada en los pueblos indios de encomenderos cercanos a Cortés. Con todo, los franciscanos y, en especial, los del con-

5 AGI, Patronato, 211, R. 11 (Ejecutoria y otros papeles de las sentencias, acusación del 26 de julio de 1566). 
vento de Texcoco, apoyaban activamente la coalición. A mediados de julio de 1566, la tensión había llegado a su culmen, de manera que el martes 16 de julio los jueces procedieron al arresto de una veintena de sospechosos. Las repetidas condenas pronunciadas contra el Marqués insistían en la coincidencia de que había signos fehacientes pues el acusado se comportaba ya como un rey: durante ciertos oficios, pedía que le trajeran el misal del altar, lo que estaba reservado a los príncipes; con ocasión del bautizo de sus gemelos mandó construir una galería entre la casa y la iglesia de México, como lo habría hecho un rey; usaba un sello de mayor tamaño que el de un marqués; en los pueblos sujetos a sus dominios, hizo que quitaran los blasones del rey de Castilla para poner los suyos.

La colación a la indiana que Alonso de Ávila ofreció a Martín Cortés el primer domingo de noviembre de 1565 dejó pasmados a los oidores. A la caída de la noche, Ávila entró en México en compañía de entre 24 y 30 caballeros y arcabuceros disfrazados de indios. Acompañada de numerosos indígenas procedentes de los pueblos del conspirador, la tropa traía infinidad de platos suntuosos como ofrenda al Marqués y a su esposa. Resultó increíble para un rico encomendero que los alfareros indios de Cuautitlán fabricaran para la ocasión toda la vajilla de barro, donde se sirvió el banquete. Los vasos y cántaros llevaban la letra $\mathrm{R}$ a modo de decoración. Las garrafas llevaban inscrito el anagrama REIAS, al que se le superpuso el detalle de una corona. Llevaba también este anagrama una $\mathrm{N}$ sobre la letra $\mathrm{A}$, lo que según los oidores significaba Reinarás. Entre los invitados de honor figuraba, ante todo, el licenciado Valderrama, comisario del rey y visitador de Nueva España. 
Durante días, los jueces de México estuvieron convencidos de que la fiesta hadaba la ruina de la Audiencia, por lo que no descansarían hasta saber quién había asistido a la misma. Además de la vulgata judicial que relataban los testigos, algunos aportaron un sinnúmero de precisiones. El licenciado Espinosa, que había preparado la llegada de Ávila, explicó que la feliz tropa había hecho un alto en la parroquia de Santiago. Ávila estaba disfrazado de cacique indio, a diferencia de otros caballeros, y se arrodilló ante el Marqués en el momento de recibir a la tropa: una escena que recordaba la sumisión de Moctezuma ante Hernán Cortés. Espinosa narró la respuesta que Ávila dio a varios caballeros que halagaban la opulencia del convite: "Bienes nos hartaremos e nos demos un hartazgo. Pues el rey nos quiere quitar la comida, hartémonos primero". Nadie podía obviar el significado de la escena de homenaje del falso Moctezuma a Martín Cortés, como tampoco la metáfora política del convite pantagruélico. Al final, la velada alcanzó probablemente un centenar de comensales, hombres y mujeres, un número bastante superior al de aquellos que estaban en la privanza del Marqués. Una vez terminados los ágapes, la mascarada continuó su curso con gran alboroto en las calles de México. Estaba demostrado que los pueblos de las encomiendas constituían la trastienda de la insurrección, una frontera de autoridad interna dentro de los territorios de la corona, más allá de la cual los agentes del rey de Castilla no detentaban ningún poder. Llegado el momento, los conspiradores no habrían tenido dificultades para eliminar a los oficiales del rey, por lo que se calificó a cada uno de estos hechos de rebelión.

La primera acusación dirigida a Cortés, el 26 de julio de 1566, solicitaba su ejecución directa y la confiscación de la 
totalidad de sus bienes. El proceso mexicano prosiguió en Madrid, al tiempo que transfirieron al condenado a la Península junto con una decena de otros acusados. Según dos órdenes, de 23 y 27 de septiembre de 1571, condenaron al reo al exilio perpetuo de Indias, a diez años de servicio en el ejército de Su Majestad, y al embargo de sus bienes. La apelación fue rechazada el 24 de septiembre de 1572 en una sentencia definitiva en grado de revista, y las condiciones por las que debía purgarse la pena se precisaron en diversos autos. Martín se dirigiría al presidio de Orán en un plazo de tres meses y pagaría una multa de 50000 ducados, así como los gastos de justicia, decisión que fue confirmada en marzo de 1573. Otros textos fijaron cuál sería el detalle de las incautaciones y el total de sumas que debía en concepto de gastos de justicia. ${ }^{6}$ Una vez emprendido el camino hacia Orán y pagado 20 lanzas para servir contra los moros, se le redujo la pena, por lo que el Marqués pudo regresar a Madrid a principios de 1580. Mientras tanto, el Consejo de Indias sacaba brillo a las armas de las audiencias desarrollando su argumentación jurídica.

Sin querer entrar aquí en la tergiversación de los textos castellanos y latinos, detengámonos en la argumentación presentada contra el Marqués y en la condena aprobada por el Consejo de Indias en 1571, 7 pues fue uno de los escasos textos que calificaron la rebelión como crimen de lesa maiestatis.

${ }^{6}$ AGI, Patronato, 208, R. 1, ff. 46-49 (acusación del fiscal, 26 de julio de 1566), Patronato, 211, R. 11 (testimonio presentado en México por el licenciado Arteaga Mendiola, $1^{\circ}$ de octubre de 1573, sentencias) y Patronato, 171, N. 1, f. 20.

7 AHN, Documentos de Indias, Diversos-Colecciones, 39, N. 1, ff. 116126 (La culpa que resulta contra don Martín Cortés...). 
La instrucción demostraba la correspondencia existente entre las pruebas particulares y las generales - la notoriedad de los hechos - contra el condenado, es decir, sin la menor duda, la conjura se había llevado a cabo. En nombre de esta correspondencia, admitieron a los delatores como testigos de cargo válidos y sus afirmaciones prevalían ante toda dificultad relativa a las pruebas particulares. Las infracciones simbólicas al respeto de la autoridad del príncipe eran reales, ya que atestiguaban de la premeditación y del carácter secreto de la conjura. Los autores más importantes de tratados sobre la tiranía coinciden en este punto. ${ }^{8}$ La ignominia del delito se manifestaba de manera aún más notoria cuando se cometía en un reino que, alejado de la persona del rey, había vivido en paz hasta la llegada del Marqués. El que no hubiera conseguido alcanzar su propósito no anulaba el ardid, es decir, la rebelión por la palabra, tal como fue definida ante todo por el jurista pisano Bartolo Sassoferrato. Había, pues, que proceder contra el traidor de la misma manera en que se hacía en los casos más execrables (in tracta quomo in crimi. les maiest). A los delitos de palabra se añadían los hechos de complicidad y la duración del complot, que permitín que este último se clasificara como una de las conjuras más atroces. La gravedad de tales casos aseguraba así la legitimidad del recurso a la tortura.

Las pruebas menores bastaban entonces para pronunciar las penas ordinarias (minor probatio est sufficiens ad panam ordinariam doctri vulga) y recibir a todos los testigos, los criados, los vasallos, los moros, e incluso a los criminales (in causa

8 AHN, Documentos de Indias, Diversos-Colecciones, 39, N. 1, f. 137 : "Egidi Boffi. in sua practi. Crimi. intitu. de crimi. Les. Maiesta [...]; Hieroni Gigan. in tracta de crimi. Lesa. Maiesta...; Bar. in d. tracta de Tyranide". 
conspirationis contra principem vet rempublicam admittuntur ad faciendam probationem omnes testes; servi ficdei, mauri, muberes, minores, criminosi et alia persone). La congregación armada de hombres honorables agravaba irremediablemente el delito. El jurista milanés Bossi estableció una graduación de las categorías de rebelión basada en la consideración sobre el bando de los conjurados. Los juristas del Consejo de Indias juzgaron que la mayoría de los rebeldes eran caballeros e hidalgos, gentileshombres que pertenecían a familias de renombre. El orden social de los nobles y títulos se incluía en la majestad concebida como un conjunto jerárquico. ${ }^{9}$ Elevada al rango de atributo carismático del poder, la majestad se extiende al amplio campo de la potestas, el del ejercicio de la autoridad del príncipe. El derecho del crimen de lesa majestad no afectaba, pues, solamente a la persona real. La protección se extendía a la totalidad del grupo de los que detentaban una parte del poder del rey. Las élites y los representantes del soberano conformaban así el sólido cimiento de la Majestad que se erigía, en la abstracción, de modo metafórico. La ruptura de las relaciones de la majestad constituía, de esta manera, una forma gravísima de crimen lesa maiestatis. El texto confirmaba la aceptación de toda declaración depuesta in articulo mortis. Alonso de Ávila confirmó su acusación de Cortés a los pies del cadalso. Según los jueces, este tipo de proclamación última (ultimo dicto et confessioni testis) conservaba toda su fuerza, en especial cuando se trataba de una declaración en

9 Thomas, “L'institution de la Majesté”, pp. 331-386; Sbriccoli, Crimen lesae maiestatis, tercera parte. 
los umbrales de la muerte (maxime in articulo mortis), ya estuviera ésta debidamente recogida, o no, ante notario. ${ }^{10}$

Al final, los jueces del Consejo de Indias no olvidaron subrayar las incoherencias del detenido y su defensa, las cuales demostraban que no había duda sobre la culpabilidad de Cortés. En su confesión, varios testigos contra los que se devolvió la acusación de complot hablaron de proyectos de rebelión. La culpabilidad con la que incurrían en las penas ordinarias más graves residía en el simple hecho de no haber denunciado hasta entonces nada, la culpa sciencia, sobre todo cuando se encontraban juntos en numerosas manifestaciones, convites y otros juegos, lo que excluía que el Marqués pudiera alegar que eran todos enemigos declarados. Una actitud disuasoria que revelaba el gran doblez del Marqués. Cortés había mentido en diversas ocasiones y varios de los testigos habían hecho declaraciones delusivas, acusando falsamente a Pedro de Aguilar del pecado de sodomía (pecado nefando) para recusarlo como denunciante. La arremetida judicial de Cortés se tornaba finalmente contra él. No por ello la coniuratio había desembocado en alguna contienda duradera de orden público, como la insurrección de Gonzalo Pizarro en Perú, que puso a los Andes a sangre y fuego casi durante cuatro años, siendo calificada como rebelión por los mismos contemporáneos. Hasta el siglo xix, con la publicación de diversas crónicas de los hechos, el acontecimiento no se presentó como guerra civil. ${ }^{11}$ La Península, que había conquistado a las Indias, debió así reconquistar a los españoles.

\footnotetext{
10 AHN, Documentos de Indias, Diversos-Colecciones, 39, N. 1, f. 137.

11 Gutiérrez de Santa Clara, Quinquenarios, t. II.
} 


\section{LIBERTAD DE LOS ESPAÑOLES DE INDIAS,} TIRANÍA DE LA PENÍNSULA

El control de la monarquía indiana había generado la producción de una legislación destinada a responder a las cuestiones planteadas por el trato de los indígenas, lo que suponía, de hecho, una forma de reglamentación y de jurisprudencia más que un corpus jurídico autóctono. Por lo demás, el derecho común reinaba en el mundo hispánico. Forjado por los juristas italianos y, en menor medida, por los franceses, se refería a las sumas de derecho romano revisadas por los juristas de fines de la Edad Media. ${ }^{12}$ La supremacía de este derecho consistía, ante todo, en el nuevo desempeño de la corona de Castilla para que se aplicara de un extremo a otro de las monarquías ibéricas. Así, un tema originario de Trujillo en España podía juzgarse en México; un evasor de las prisiones sevillanas deportado a Nueva España corría el riesgo de que lo arrestaran en París bajo demanda del embajador español, antes de sufrir en Amberes la pena de decapitación a la que había sido condenado en primera instancia en las Indias. Existía, pues, un marco jurídico al que Europa estaba acostumbrada y que cubría la totalidad de las realidades hispánicas. Se trata de una faceta desatendida de la globalización que ofrece una resonancia especialmente amplia a todo mecanismo de la publicística de los asuntos penales.

Los rebeldes proclamaban la libertad para subrayar precisamente su voluntad de liberarse de la obediencia y del influjo del derecho. Por lo general, el término estaba asociado a proclamas hostiles a las autoridades. Hablar libremente se identificaba con hablar demasiado, mal o, por el contra-

${ }^{12}$ Clavero Salvador, Historia del derecho. 
rio, decir sin recelo lo que cada uno pensaba en voz baja. La libertad de palabra alimentaba los rumores. Pedro de Aguilar, delator del complot de Cortés, evocaba el bullicio que animaba a México en el otoño de 1565:

Y tractando principalmente dende algunos días por esta ciudad e por las calles plazas el descontento grande que los encomenderos $[\ldots]$ tenían de una cédula $[\ldots]$ e de otra [...] algunas personas hablaban libre e desvergonzadamente sobre lo uno y lo otro diciendo que por sus haciendas e honras habían de morir $[\ldots]{ }^{13}$

El fraile franciscano Cornejo fue denunciado por el abogado de Martín Cortés por agitador de poco fiar, un individuo "muy desasosegado e inquieto e envidioso y muy suelto e libre en hablar". ${ }^{14}$ Los usos vulgares y despectivos del término se asociaban indefectiblemente a los comportamientos de los fiesteros que se habían alistado en las filas de los rebeldes. A los ojos de las autoridades, la libertad de los alborotadores sobrepasaba el ámbito político. Eran puras inconveniencias, provocaciones, desórdenes.

A la inversa, bautizaron las armas de Pizarro como armada de la libertad, nombre que tomó el destacamento del conspirador Hernández de Girón. Según varios delatores del complot de Martín Cortés, la palabra libertad significaba, en verdad, la ruptura de los pobladores con la tiranía de Felipe II. Desde la primavera de 1566, el clérigo Espinosa afirmaba que:

El dicho don Luis Cortés había de echar un bando diciendo a conquistadores e hijos de conquistadores y pobladores de la

${ }^{13}$ AHN, Documentos de Indias, Diversos-Colecciones, 39, N. 1, f. 22.

${ }^{14}$ A GI, Patronato, 211, f. 15. 
Nueva España: libertad, libertad contra la fuerza e tiranía del Rey don Felipe, e para esto allí luego [...] había toda la ciudad de jurar al dicho Marqués del Valle por Rey. ${ }^{15}$

La libertad política y judicial tenía por corolario la libertad económica. Puesto que el rey de Castilla rechazaba la perpetuidad de las encomiendas, la autonomía económica que éstas habrían podido conferir a los pobladores se confundía con la libertad política a la que aludían los rebeldes. Estos dos planos se mezclaban siempre en las proclamaciones de desobediencia. Así es como el delator Pedro de Quesada testificaba sobre las intenciones de los insurgentes:

Se daría un pregón que todos los conquistadores y pobladores viniesen a favorecerles y a gozar de la libertad dentro de tantas horas, y que les darían pueblos e perpetuidad en ellos a los que no los tuviesen, y que los que dentro de tantas horas no acudiesen se los quitarían a los que los tuviesen y los matarían, y ansí mismo que todos los oficiales e mercaderes cesasen de sus oficios estuviesen las tiendas abiertas so pena de muerte. ${ }^{16}$

Las sentencias reales que apuntaban a limitar los repartos de indios representaban muchos de los ataques a la libertad de los colonos. En 1544, el comisario Francisco Tello de Sandoval lo expresaba a su manera para el caso de Nueva España, explicando al rey que en las Indias "faltando los Indios falta todo". ${ }^{17}$ Cierto es que por el modo en que se había exagerado la inculpación de lesa majestad por parte de los jueces en

15 AHN, Documentos de Indias, Diversos-Colecciones, 39, N. 1, f. 41v.

16 AGI, Patronato, 211, f. 67.

17 Sandoval al rey, México, 26 de mayo de 1544, AGI, Patronato, 211, R. 11, N. 24, f. 68. 
defensa de los ataques lanzados por los conspiradores a los oficiales reales, los rebeldes habían extremado la acusación de tiranía contra estos mismos oficiales que habían llegado a las Indias - visitadores, oidores y hasta virreyes -, los cuales no hacían más que enriquecerse en detrimento del país. ${ }^{18}$

La conquista daba mérito a los españoles que la habían realizado y justificaba que la Península reconociera la perennidad de sus derechos sobre las poblaciones indígenas. El favor real no podía depender de consideraciones jurídicas o presupuestarias. El mérito, en realidad, excedía la dimensión real y se extendía hasta Dios, pues la conquista se había hecho en su nombre. A todo ello, el rebelde levantisco de México, Alonso de Ávila, proclamaba que "si Su Majestad no nos hacía merced, Dios nos la haría", ${ }^{19}$ de lo que se desprende que el recurso a las armas contra el rey sería una salida favorable, ya que Dios apoyaría a los insurgentes. El mérito justificaba en sí mismo la rebelión, porque desde los primeros conquistadores los favores reales que de él derivaban se extendían a todos los que habían contribuido a las guerras indianas. El mérito daba forma a la libertad de los españoles.

El movimiento pizarrista tuvo sus tratadistas para justificar la insurrección por la tiranía del rey de Castilla. El canónigo de Quito, Juan Coronel, procedía de un linaje converso del que varios miembros participaron en la rebelión peninsular de los comuneros. Entusiasmado por el ánimo de justifi-

18 Se entiende que éstos calificaban de tiranos a los capitanes rebeldes. Sobre la inculpación judicial por medio del empleo de calificación de tiranía, Salinero, La trabison de Cortés, cap. VIII, "Les guerres de rébellion".

19 AHN, Documentos de Indias, Diversos-Colecciones, 39, N. 1 (Dichos de Baltasar de Aguilar). 
car la desobediencia de Gonzalo Pizarro, redactó una obra breve en ese sentido, titulada Bello Justo. En junio de 1548, el obispo de Cuzco le prohibió ejercer toda función religiosa y lo condenó al exilio en Castilla, ${ }^{20}$ lo que no impidió que sus ideas y sus textos circularan entre los conspiradores. ${ }^{21} \mathrm{El}$ dominico Luis de la Magdalena fue condenado también en junio de 1548 y recibió disciplinamiento público en Lima. Vituperaba en el púlpito las Leyes Naturales y a las autoridades judiciales, insistiendo en que el rey de Castilla se llevaba los recursos del país para utilizarlos en otro sitio, no escuchaba a sus súbditos y tampoco reconocía el mérito de estos últimos. Esta política se hallaba en los antípodas de la que el mismo monarca había prometido, ya que renegaba de su palabra y rompía el pacto de gobierno que, de forma tácita, había establecido con sus súbditos. Con ello se adjudicaban todos los atributos de la tiranía, de modo que los españoles de las Indias podían emprender una guerra justa contra él y sus representantes, a quienes era legítimo eliminar como agentes que eran de la tiranía peninsular.

En Guatemala y en Nueva España, buena parte de los españoles, tanto encomenderos bien dotados como emigrantes pobres o soldados sin compañía, tenían en mucha estima las ideas de la doctrina pizarrista. Luis Cal, guardián del convento franciscano de Texcoco y uno de los mejores pun-

20 Colección de documentos inéditos para la historia de España, t. XLIX, Madrid, 1866 ("Documentos relativos al licenciado Pedro Gasca sobre la comisión que le dio Carlos V en 1545 para ir a pacificar el Perú, sublevado por Gonzalo Pizarro y los suyos”), p. 403 (carta de La Gasca, 7 de mayo de 1548).

21 Lohmann Villena, Las ideas jurídico-politicas en la rebelión de Gonzalo Pizarro. 
tales de Martín Cortés, se hacía eco de las páginas de Bello Justo. Se añadía a todo ello que aquellos principios de legitimación de la desobediencia se encontraban presentes, desde hacía tiempo, en las obras de juristas clásicos como Domingo de Soto y su suma jurídica (Summule), que Cal no olvidaba nunca citar, destilando de ella una versión radical:

Defenderse uno es licito e matar es ilícito, pero si defendiéndome no puedo dejar de matar, no peco matando al que me ofende, y así lo entiendo yo, que si se pusiese en ejecución la cedula justificada estaría la causa [...] podrían los conquistadores defender sus pueblos. ${ }^{22}$

Considerado como teólogo anticipado de la rebelión, el fraile daba la absolución sin confesión a los futuros asesinos de los oficiales reales.

Los indios no estaban de parte de la coalición ni del rey. El partido legalista, sin embargo, como el de la coalición, no olvidaba presentarse como defensor y aliado de los indios. Los asuntos políticos de Indias raras veces separaban en dos campos homogéneos la república de los indios y la de los españoles. La insurrección andina llevada a cabo por Francisco Hernández de Girón contra la Audiencia de Lima de 1553 y 1554 constituye un caso ejemplar en este sentido. De unos 40 años de edad, Girón nació en Cáceres (Extremadura), ciudad en especial vinculada a la conquista de las Indias y que nutría copiosamente las migraciones hacia el Nuevo Mundo. No había participado en la mítica encerrona de Cajamarca, que permitió que los españoles apresaran

${ }^{22}$ AHN, Documentos de Indias, Diversos-Colecciones, 39, N. 1, f. $54 \mathrm{v} .-55$. 
al Inca Atahualpa el 16 de noviembre de 1532. Girón llegó dos años más tarde, pero lo suficientemente pronto como para ser reconocido representante del círculo cerrado de los “primeros conquistadores de estos reynos”. Contribuyó a la pacificación y poblamiento de las regiones de Arequipa, Quito y Popayán, dirigiendo una guerra cruenta contra los indios. Asumió así las funciones de lugarteniente del gobierno local. Dotado de una encomienda por Francisco Pizarro, administraba el distrito de Popayán cuando el virrey Núñez de Vela lo invitó a unirse a sus tropas para luchar contra la insurrección de Gonzalo Pizarro, al que capturó y liberó tras la muerte del virrey. Se esmeró entonces en pacificar la región de Popayán, alborotada en varias ocasiones por revueltas de indios. A su llegada a Panamá, el comisario La Gasca lo reclutó para continuar el combate contra Gonzalo Pizarro. Se unió al presidente en Xauxa y lo apoyó militarmente hasta la victoria final de Xaquixaguana. Como premio a sus servicios, La Gasca le concedió la custodia de los indios que Pizarro tenía en su provincia de Quito.

En Cuzco, el domingo 12 de noviembre de 1553, Francisco Hernández Girón había estropeado la boda de Alonso de Loaysa, sobrino del arzobispo de Lima. Acompañado de una veintena de hombres, se apoderó del corregidor Gil Ramírez, con la idea de reenviarlo a Lima para demostrarles a los oidores que el magistrado no era bienvenido en Cuzco. Girón también mandó eliminar al tesorero Juan de Cáceres. Como la mayoría de los insurgentes, Girón basaba su legitimidad en su elección por el cabildo, en tanto que juez superior y representante de Cuzco. De inmediato dispuso de un millar de hombres, de los cuales 230 eran negros instruidos en el manejo de las armas por los españoles. A estos 
hombres vinieron a unirse un número importante de indios, probablemente varios millares, reclutados por mano de los caciques. El retén de los oidores de Lima hizo lo mismo, de manera que durante los combates, Girón mandó ahorcar a muchos indios que pertenecían a las tropas legalistas. A partir del invierno de 1553, el mariscal Alvarado solicitó 7000 indios a los caciques de la región de Charcas para el servicio de la tropa reclutada contra Girón, los cuales formaban el personal necesario en la intendencia de los ejércitos. En lugar de gastar pólvora en salvas, matar a los indios del enemigo era una forma de privar al ejército de intendencia.

Los insurgentes avanzaron primero desde Cuzco hasta las puertas de Lima, sin asediar la ciudad. Durante un año, el conflicto armado se materializó en una serie de escaramuzas criminales, de las que Francisco Hernández de Girón parecía salir siempre victorioso. Sin embargo, lo apresaron en Xauxa en diciembre de 1554. Luego, lo interrogaron, juzgaron y decapitaron en Lima. Su tropa sufrió un lento desgaste, ya que sus hombres respondían paulatinamente a las ofertas de perdón y recompensa que el campo legalista les lanzaba para instarlos a desertar. Al menos, casi 500 españoles y 2000 indios encontraron la muerte en los movimientos insurreccionales, desde la rebelión de Sebastián de Castilla en Charcas, en 1553, hasta el arresto de Francisco Hernández de Girón en 1554. Según parece, el balance de la insurrección anterior de Pizarro excedió de por sí tales cifras.

La incorporación a las funciones de intendencia no evitaba de ninguna manera que los grupos indígenas jugaran con sus propias bazas en los conflictos. El cronista Felipe Huamán Pomán de Ayala indica que su padre se puso al frente de sus indios lucanas para servir al rey de Castilla. Otros 
caciques de la región de Andahuaylas, Apo Uasco Changa y Guamán Uachaca Lurinchanga, hicieron lo mismo después de la batalla de Chuquinga. Los lucanas infligieron entonces varias derrotas a las tropas de Hernández de Girón. Según la crónica, a principios de diciembre de 1554, fueron los indios quienes obligaron a los rebeldes a huir aún más lejos, hacia la zona montañosa de Xauxa. Fueron vencedores de "trecientos españoles y cien yanaconas mestizos y mulatos del bando de Hernández de Girón en el alto de Uachauapite”. Huamán Pomán precisa que los indios xauxa fueron los primeros en prender a Hernández de Girón antes de entregárselo a los españoles. El cronista mestizo describía así la acción de los indios como favorable al partido del rey de Castilla. Sea como fuere, se mostraban perfectamente capaces de servir a cada uno de los bandos beligerantes, o de atacar al mismo tiempo a los españoles. Aprovechando los combates entre pobladores, los lucanas habrían desalojado a los hombres del campo legalista del capitán Alvarado al margen de la batalla de Chuquinga. ${ }^{23}$ Sus ataques se sucedieron durante las décadas de 1560 y $1570^{24}$ y con ello incubaron, con toda seguridad múltiples resentimientos contra cada bando.

${ }^{23}$ Huamán Pomán de Ayala, El primer y nueva corónica y buen gobierno, p. 433; "La Crónica India”, La Prensa (Lima) (20 nov. 1946), y Porras Barrenechea, El cronista indio Felipe Huamán Poma de Ayala, p. 7.

${ }^{24}$ Evocación de varios ataques de los lucanas contra las tropas reales según una información de Bartolomé de Pineda en 1577: Revista de Archivos y Bibliotecas, t. I, p. 189, citado por Porras BarRenecheA, El cronista indio Felipe Huamán Poma de Ayala, p. 8. 
GOBERNAR LAS INDIAS DE CASTILLA

Desde 1540 hasta 1580, la corona de Castilla debió luchar sin cesar contra las desobediencias para establecer un gobierno duradero. ${ }^{25}$ La proclamación de las Leyes Nuevas en un contexto de insurrección es perfectamente reveladora de tales dificultades. Tres principios se afirmaban en ellas con fuerza: aquellos que habían maltratado a los indios debían permanecer privados de las leyes, al igual que los rebeldes de Perú; ningún virrey ni gobernador podía atribuir reparto de indios por su cuenta a partir de entonces; para terminar, "al morir un español que tenía indios, esto volverían a la corona" ${ }^{26}$ Aunque las Leyes Nuevas no se hayan mantenido, no hay que menospreciar ni sus efectos positivos ni su espíritu. En una serie de textos, la corona mandó que se liberara a los esclavos indios que se encontraban en las minas, luego, a todas las mujeres y niños de menos de catorce años que habían acabado prisioneros. ${ }^{27}$ En marzo de 1551, el activo Bartolomé Melgarejo, conocido como el procurador de los indios, se encargó de poner todo en marcha para

${ }^{25}$ En realidad, la administración de Indias debe imponerse con infinitos ajustes, distanciamientos y contradicciones, como lo ha mostrado en particular Pietschmann, El Estado y su evolución. Más recientemente, en el marco de una historiografía de los saberes de Estado, y no sin debates, Arndt Brendecke ha enfatizado los límites de la información institucional que se buscaba desde la península ibérica (Imperium und Empirie. Funktionen des Wissens in der Spanischen Kolonialherrschaft).

${ }^{26}$ Cortés había distribuido más de 500 encomiendas sin tener derecho a ello, algo que Carlos V le había reprochado. Himmerich y Valencia, The Encomenderos of New Spain, p. 3; Francisco Pizarro hizo lo mismo. ${ }^{27}$ Cédula del 16 de abril de 1550, renovada el 7 de julio de 1551 y el 17 de marzo de 1553. Sarabia Viejo, Don Luis de Velasco, pp. 303 y ss.; S. Zavala, Los esclavos indios en Nueva España, pp. 123 y ss. 
luchar contra los abusos y conseguir liberar a los prisioneros. Unos 60000 esclavos indios constituían la población servil de Nueva España a mediados de siglo. Parece verosímil, pues, que se sitúe entre 20000 y 30000 el número de remisiones que se realizaron a principios de la década de $1560 .{ }^{28} \mathrm{Las}$ prescripciones de las Leyes Nuevas acrecentaron, de manera extraordinaria la notoriedad de los oidores, los cuales formaron y aplicaron interrogatorios hasta el punto de conocer al detalle el estado de la sociedad colonial, la extensión de las encomiendas y el comportamiento de los pobladores. Tal evolución no podía sino exacerbar las tensiones entre los oficiales del rey y las familias de los conquistadores, considerados como la única aristocracia del país.

En el aspecto práctico, las audiencias no se beneficiaban de ningún medio suplementario para la ocasión. No estaban en condiciones de garantizar aquella vigilancia general de las cuestiones indianas, como tampoco parecían estar siempre deseosas de ejercerla. Aun así, más allá de sus funciones judiciales, las audiencias garantizaban el gobierno efectivo de las monarquías indianas. Al mismo tiempo, era de esperar que los hombres investidos de una autoridad real particular rigieran las nuevas leyes. Con este objeto, Blasco Núñez de Vela fue nombrado virrey de Perú en marzo de 1544. Contando a sus espaldas con su experiencia peninsular de inquisidor, Francisco Tello de Sandoval fue nombrado visitador (comisario) para Nueva España, a donde llegó en marzo de 1544. Como nuevo presidente, en la primavera de 1548 se le adjudicó a Alonso López de Cerrato la tarea de instaurar la ley para la Audiencia de Guatemala, también llama-

28 Byrd Simpson, Many Mexicos, p. 58, y Sherman, "Indian Slavery and the Cerrato Reforms”, pp. 25-50, estimaron 60000 cautivos. 
da Audiencia de los Confines. A falta de hombres, medios y paz, la aplicación de este conjunto legislativo se suspendió rápidamente, ya que no fue abolido, de modo que siguió inspirando la política americana de la Península y atizando de muchas maneras las rebeliones.

Una serie de cartas del licenciado Francisco Tello de Sandoval al rey nos permite conocer hoy las trabas impuestas a la aplicación de las leyes en Nueva España, la fragilidad del gobierno de las Indias, así como el estado de ánimo en el que se encontraban los españoles..$^{29} \mathrm{El}$ visitador subrayaba los abusos pertrechados contra los indios y afirmaba que la reforma llegaba a su peor momento, habida cuenta del estado general de debilidad de la administración real. Las epidemias reducían la actividad del país. Se estimaba en 160 o 170 el número diario de fallecidos en los diferentes barrios de México. Cada uno admitía que 200000 indios, como mínimo, habían perdido la vida desde el principio de la epidemia y los bastimentos escaseaban terriblemente. Cerca de México, los indios pensaban que su encomendero era el rey del país. No sabían lo que podían esperar de la justicia del rey de Castilla. Es lógico que el comisario afirmara la necesidad de reforzar el sistema reticular de las provincias y hacerlo más coherente. Los abusos también los cometían los propios indígenas. Según Sandoval, el poder de las élites tradicionales debía reducirse, así como las exacciones de los hijos de los conquistadores. Caciques y jefes principales eran los culpables de cobrar la parte de los tributos destinada a las comunidades autóctonas.

Las carencias de la administración se traducían en el hecho de que la Hacienda no conseguía pagar los salarios de los

29 Sandoval al rey, México, 26 de mayo de 1544, AGI, Patronato, 211, R. 11, N. 24, f. 68. 
oficiales, haciendo imposible cualquier refuerzo del aparato judicial. La corona recibía de las Indias más de lo que le pagaba, por lo que Sandoval sugirió que se repartieran los salarios de algunos oficiales, mejorando los emolumentos de los que cobraban menos. Había que hacer que se integrara el principio que prohibía a los agentes del rey que tuvieran intereses personales en los asuntos locales, pero las finanzas no estaban por todas partes. Los hombres honorables, cultos y deseosos de obrar bien debían ocupar los puestos, una situación que estaba lejos de aquella realidad. De esa manera, los conquistadores casados, exentos de encomienda, aunque premiados por la corona con cargos de corregidores, eran de los más crueles en el trato con los indígenas. Todos se acordaban también de los desengaños que habían ocasionado las fundaciones de las diversas audiencias. Núñez de Guzmán, primer presidente de la de México, tuvo un comportamiento tan detestable que hubo que destituirlo en 1530. Los oidores debían ser "personas de letras e conciencia y experiencia, que hayan tenido cargos con grado de justicia porque hay falta de personas de experiencia y por ellos algunas veces ha habido falta en la expedición de la justicia”. También debían seleccionarse los alcaldes de Indias con mucho más cuidado que los de Castilla, ya que estos últimos estaban más cerca del rey.

El esmero que debía tenerse en estas elecciones se mostraba crucial, en tanto que la ocupación de los cargos era bastante irregular. Entre 1544 y 1547, tan sólo cuatro oidores ocupaban sus cargos. De 1534 a 1540, ningún fiscal titular había asistido a la audiencia. Entre 1553 y 1556, Nueva España fue dotada de únicamente un procurador interino. Hubo que esperar a 1566 para que el licenciado Luis Maldonado se instalara en ella como titular. En un contexto tan deletéreo 
como éste, el virreinato incurría en grandes riesgos. En varias ocasiones, Sandoval se sorprendió de la relativa tranquilidad del país y preconizó una política de acomodo: “Es de tener en mucho que las cosas del Perú no hayan alterado a esta Nueva España; según la gente della, estaba triste y descontenta, pero hase tenido cuidado de darles buena esperanza y también como se tienen por muy leales vasallos de SM". ${ }^{30}$ A pesar de las advertencias, numerosos condenados de Perú fueron exiliados a México.

Aquellas carencias crónicas no sólo estaban lejos de desaparecer, sino que se prolongaron de forma diversa a lo largo de los siguientes decenios. El mandato de Pedro de la Gasca, comisario del rey dotado de todos los poderes y presidente de la Audiencia de Lima, enviado a Perú para sofocar la rebelión de Gonzalo Pizarro, es particularmente ilustrativo de las contradicciones de la política indiana de la Península. El presidente ganó gloriosamente la batalla de las armas, sin embargo, su acción se saldó con un tipo de capitulación política y social. Desde su llegada a Panamá, en agosto de 1546, atrajo a numerosos capitanes disidentes de Pizarro. Durante la batalla de Xaquixaguana, se apoderó de los últimos insurgentes y luego, el 9 de abril de 1548, mandó decapitar a Gonzalo Pizarro. La Gasca reunió a una asamblea en Cuzco para proceder a la fijación del total de las pensiones de cada encomienda, la tasa de las encomiendas. Tras el trabajo de los 72 oficiales de la Hacienda, se informó a los encomenderos y a los propios indios de las nuevas tarifas aprobadas para prevenir los abusos. Sin embargo, la evaluación escondía nuevos

30 Sandoval al rey, México, 26 de mayo de 1544, AGI, Patronato, 211, R. 11, N. 24, p. 2. 
traspasos de propietarios y la multiplicación de las derogaciones de las Leyes Nuevas.

Los repartos mayores de los indios persistieron y el número total de encomiendas siguió aumentando. El 16 de agosto de 1548 , tras su victoria, La Gasca procedió a una amplia redistribución de indios. Durante su reparto de Guaynarima, concedió a sus capitanes y soldados más de 1000000 de pesos en ingresos de encomiendas. En 1540, existían oficialmente 274 encomiendas en Perú; en 1570, la cifra alcanzó los 464 repartos. En la región de Cuzco, así como en la zona de Lima, eran cuantiosas las superiores a un millar de indios y las extracciones que se hacían en ellas seguían superando las cantidades fijas. ${ }^{31}$ A falta de ejército real en las Indias, la corona no podía quitarles las encomiendas a los españoles y, a la vez, buscar su apoyo militar. En el camino de regreso, en enero de 1550, La Gasca declaró, para quien quisiera escucharlo, que se habían pacificado los Andes. En cambio, numerosos factores obstaculizaron el asentamiento de una verdadera pacificación. La política de recompensas no bastaba para contentar las ambiciones de unos y las miserias de otros. Por ello, aunque en 1548 recibió buena parte de los ingresos de Gonzalo Pizarro para el apoyo que había aportado al partido legalista, el capitán Francisco Hernández de Girón lideró en 1553 y 1544 una de las rebeliones más criminales que vieran los Andes.

En cambio, el comisario había ganado la batalla de la Hacienda cobrando los impuestos reales. Necesitó más de 1500 llamas y casi 3500 cargueros para transportar las barras de plata y oro del rey hacia los embarcaderos, con destino a Cas-

31 Barnadas, Charcas; Puente Brunke, Encomienda y encomenderos. 
tilla. ${ }^{32}$ Más de 1000000 de pesos salía así de los Andes en beneficio del derrochador Carlos V, es decir, la cantidad más elevada, jamás cobrada, desde los tiempos de los convoyes que sucedieron a la ejecución del inca Atahualpa. Aquello no hizo más que reavivar el sentimiento de que el rey, que desatendía las Indias, robaba el dinero a los pobladores para resolver asuntos lejanos, sin garantizar al país un gobierno estable. ${ }^{33}$

Dispersar a los hombres peligrosos para prevenir la insurrección fue uno de los principios mayores de la política de La Gasca. Había que vaciar la tierra de individuos peligrosos. Sin embargo, el flujo de los advenedizos no dejaba de crecer. En 1548, el mariscal de campo Alvarado estimaba en 2000 el número de españoles en los Andes. A fines del año 1555, el Marqués de Cañete evaluaba su número en más de 8000 , de los que 480 poseían los repartos de indios y, de hecho, en una carta, concluía que "no hay más de 1000 españoles que tienen de comer". Al mismo tiempo, por un efecto dominó ampliamente subestimado por el presidente, el destierro de los rebeldes provocó un contagio conspirador sin precedentes. Entre la primavera y el invierno de 1548 se llevaron a casi 400 prisioneros (por más de 700 penas) desde los Andes hasta Arequipa, con la idea de embarcarlos allí. Sin duda, más de la mitad escapó de las garras de la adminis-

32 Calvete de Estrella, Rebelión de Pizarro en el Perú.

33 El virrey de Perú, Blasco Núñez de Vela, fue asesinado en enero de 1546; Antonio de Mendoza, que llegó en septiembre de 1551, murió en julio de 1552; Andrés Hurtado de Mendoza, Marqués de Cañete, nombrado en marzo de 1555, fue citado el 27 de enero de 1559. Le sucedieron Diego López de Zúñiga y Velasco, Conde de Nieva, de 1558 a 1564, encausado finalmente por corrupción, y Francisco de Toledo, de 1568 a 1580 . 
tración judicial, de modo que un flujo importante de proscritos irrigó toda la América Central. Al ser tan deseada por los conspiradores, la alianza con aquellos hombres de Perú cimentaba todas las insurrecciones. Tras la marcha de La Gasca, las rebeliones resurgieron con más ímpetu, pero con menor alcance que la del movimiento pizarrista.

Las rebeliones de importancia disponían de bases sólidas para establecer un gobierno. No carecían de ideas ni de puntos de vista para organizar la administración de las Indias en su beneficio. Cuando apresaron al inca Atahualpa, los Pizarro no habían terminado de someter Perú. La presencia del primer virrey de Perú, Blasco Núñez de Vela, sólo fue un breve intermedio. Habiendo llegado en 1544, fue decapitado el 18 de enero de 1546, tras la batalla de Iñaquito, contra las tropas rebeldes de Gonzalo Pizarro. En sentido inverso, el clan de estos últimos, los Pizarro, había echado raíces en el país. Por no poder conceder encomiendas a nombre propio, el gobernador Francisco Pizarro lo hizo al de sus esposas, sus hijos, sus hermanos y otros muchos miembros de su clan. Francisco y Hernando se apoderaron de los sectores más ricos en cada área agrícola, ganadera y minera, con el empeño de acumular las producciones complementarias. Sin duda, es necesario estimar en más de 60000 el número de indios tributarios reunidos en las encomiendas de los hermanos Pizarro en 1540. ${ }^{34}$ Sólo la de Chuquiabo, cerca del lago Titicaca, que estaba en manos del propio Francisco, reunía en una veintena de pueblos indios a más de 10000 aymaras. Igual que en el Marquesado de Cortés, que reagrupaba también a más indios de los que la corona había concedido al

34 Varón Gabai, La ilusión del poder. 
conquistador, todo estaba bastante lejos de responder a una simple lógica de acumulación, sino que apuntaba a garantizar un control político y militar de Perú..$^{35}$ La geografía de la insurrección de Gonzalo se apoyaba por todas partes en las posesiones de los cuatro hermanos. Los pueblos indios, cuyos ingresos eran considerables, servían de lugares discretos de reagrupamiento y de escondite para los que preparaban un asalto al poder.

El bando de los Pizarro se apoyaba en los concejos de ciudades fundados en el momento de la conquista que fueron ocupados por compañeros de Pizarro. Ocurría lo mismo con los cargos locales de mando (capitán, coronel, teniente de gobernador) y con los de gobernadores militares (gobernador, capitán general y adelantado) que confería la corona. Casi la mitad de los hombres que habían participado en la captura del inca Atahualpa ocuparon cargos municipales en Perú. En Cuzco, 13 de ellos eran consejeros de la ciudad, de los cuales, dos pertenecían a la servidumbre del gobernador. ${ }^{36}$ Los Pizarro estimaban mucho a la orden de los dominicos y a la de la Merced, por lo que en Perú dotaron a sus conventos de limosnas y rentas. Fue lo que ocurrió en el caso de Cuzco, donde el hermano Gaspar de la Merced, encargado de la institución durante la década de 1540, predicaba en favor del clan y decía sin falta una misa por la vida y la salud de cada uno de los hermanos. En las redes españolas se añadían las alianzas entre indios. Pronto, al advertir las fracturas del mundo autóctono, se acercaron a los grupos que no

\footnotetext{
35 Sobre el Marquesado de Cortés, García Martínez, El Marquesado del Valle.

${ }^{36}$ Lockhart, The Men of Cajamarca; Lohmann Villena, Los regidores perpetuos del cabildo de Lima, pp. 35-40.
} 
habían apoyado el ascenso al poder del inca Atahualpa. Fue lo que pasó en el caso de Cañaris. El clan encontró también valiosos aliados entre los indios del sector del fértil valle de Huaylas, situado al norte de Perú. La rebelión de Gonzalo Pizarro se nutrió de tropas indias originarias de las mismas localidades.

En un primer momento, entre el otoño de 1544 y la primavera de 1547, Gonzalo Pizarro obtuvo todos los votos, teniendo que acumular así todas las victorias. En el mes de mayo de 1544, fue nombrado capitán general y luego procurador general de Cuzco. Al final de junio, recibió todos los poderes y el título de justicia mayor, lo que le permitió formar un ejército con cientos de hombres. En septiembre de 1544, los partidarios de Pizarro aclamaron al caudillo en Huamanga como gobernador y liberador de Perú tratándole de Su Señoría. A pesar de que buena parte de su tropa lo incitaba a proclamarse soberano del país, Gonzalo Pizarro no dio nunca el paso adelante. Gobernaba en nombre del rey de Castilla contra los oficiales locales, facinerosos y corruptos.

En un segundo momento, entre la primavera de 1547 y la de 1548, Pizarro desveló su verdadera intención. Las exacciones de los capitanes, que jugaban a los bolos con las cabezas de los legalistas decapitados, aterrorizaban a los Andes. Por todas partes amenazaba su régimen. Con su llegada a Lima, la audiencia dejó de reunirse. El nuevo gobernador ejercía todos los poderes con el apoyo de un consejo constituido de personas allegadas, letrados y capitanes. La cabeza de la rebelión no se distinguía por una doctrina coherente, sin embargo, como hemos dicho, no carecía de justificaciones para legitimar el uso del poder ejercido por los españoles de las Indias. 
Para los rebeldes, era necesario loar lo que sería su práctica de poder con la idea de atraer a las poblaciones y justificar así un gobierno que reposara sobre bases diferentes al de la Península. El derecho ancestral de la conquista y primer poblamiento constituía el argumento más esgrimido en defensa del movimiento. Los testigos de los diferentes procesos repetían esa idea hasta la saciedad. El mérito de la conquista se transmitía de padre a hijo y de hermano a hermano. Gonzalo Pizarro usaba ese argumento y Martín Cortés también lo hacía. En 1585, el mestizo Miguel de Benalcázar pretendió gobernar la región de Quito y proclamarse rey allí, con la excusa de que su padre había conquistado la zona de Popayán.

La defensa de la estabilidad de un reino podía legitimar de veras el asalto al poder de un simple capitán, habida cuenta de que la historia solía acudir en ayuda de lo político. El oidor Vázquez de Cepeda, que se unió a la conspiración de Pizarro, predicaba que los reyes de Castilla habían asentado su poder en una vieja tiranía. También leía a Pizarro la Historia imperial y cesárea, así como la historia romana de Pedro Mexía. El mismo hijo del autor, que respondía al nombre de Hernán Mexía de Guzmán, fue reclutado para unirse a la tropa de la conspiración. La obra relataba la gesta de Escipión el Africano y la de Pompeyo. Otros personajes más, como Julio César o Diógenes de Siracusa, que gobernó Sicilia con mano de hierro, se erigían como valiosas referencias, evocadas por los letrados de la conspiración. Había en la raíz de la cuestión política una violencia fundadora, ataviada ulteriormente por la grandeza y la pureza necesarias para asentar la autoridad de los soberanos. Los franciscanos del convento de Texcoco, así como el encomendero Alonso de Ávila, que atizaban el complot de Martín Cortés, predicaban esta convicción bastante extendida. 
Cada una de las rebeliones importantes generó una retórica del buen gobierno. El ejercicio del cargo de poder en manos de los rebeldes contra los oidores o el propio virrey dependía de la necesidad. El rey debía escuchar a sus súbditos sin las trabas de intermediarios malintencionados. A ello se unía el principio expresado en Perú en 1544 por el licenciado García de León, en una carta dirigida al rey, de la cual la Representación de Huamanga, constituía un auténtico manifiesto de la corriente pizarrista: lo que incumbía a todos los individuos debían aprobarlo todos ellos. En castellano o en latín (quod omnes tangit, ab omnibus debet approbarit), sus versiones fueron retomadas una y otra vez por los condenados de México. El buen gobierno no podía ser otro que el de los españoles del país:

Vuestra majestad sepa que los jueces que a estos reynos nos provee no tienen cuidado de hacer justicia [...] vienen tan ambiciosos y codiciosos por faltarles la experiencia de las cosas destas partes que parece sería VM más servido en mandar proveer a cada reyno su natural: a éste, hombres de las Indias, como en España se proveen españoles. ${ }^{37}$

Ahí estaba una de las discrepancias a las que recurrían los pobladores para atacar a los oficiales reales. Por un lado, el conocimiento del país y los méritos acompañaban a los españoles de Indias; por otro estaban la ignorancia y el oportunismo de los letrados que acababan de llegar de la Península. En todo caso, aunque fuera bajo formas diversas, todos retomaban el argumento.

37 AGI, Patronato, 192, R. 1, N. 44, s. f., p. 5 (carta de Benalcázar, gobernador de Quito, al rey, septiembre de 1546). 
Los juristas españoles, como Francisco de Vitoria, habían defendido las ideas de la corriente teocrática medieval que hacían del papa el Dominus orbis, el único que podía eximir a un rebelde de su obediencia al rey de Castilla. El corpus castellano de Las siete partidas afirmaba que el pontífice podía conferir la soberanía de un territorio en la medida en que los dominios concernientes no dependieran de la autoridad de ningún monarca cristiano. No obstante, mediante una serie de bulas, Roma había dado al rey de Castilla la custodia de los territorios situados al oeste y al sur de un meridiano situado a 100 leguas de las Azores y de Cabo Verde, así como el patronato real de las Indias, es decir, la administración y los nombramientos eclesiásticos en los nuevos territorios. ${ }^{38}$ Aun así, el franciscano Joost de Rickje había incitado a Gonzalo Pizarro a recurrir a la Santa Sede para que los súbditos de Perú fueran liberados de la soberanía del rey de Castilla. Una delegación presentaría al pontífice la demanda de investidura hecha por Gonzalo Pizarro en el nuevo reino, acompañándola de la oferta de una razonable cantidad de dinero. La busca de un cambio en la custodia de los territorios y del patronato del soberano se situaba también en el centro del complot del Marqués Martín Cortés. Los testigos confirmaban el proyecto de Cortés de enviar al papa 20000

${ }^{38}$ Las bulas Inter Certera, del 4 de mayo de 1493, y Universalis Ecclesix, del 5 de agosto de 1508; "todas estas islas y Tierras Firmes descubiertas [...] desde la dicha línea [a las 100 leguas] hacia el Occidente y el Mediodía [de las Azores y del Cabo Verde], que no fueran tenidas por otro Rey o Príncipe cristiano hasta este tiempo del nacimiento de nuestro señor Jesús Cristo del año de 1493 [...], por la presente las damos y concedemos y asignamos perpetuamente à Vos [...]", bula Inter Cetera, AGI, Patronato 1, R. 3 . 
ducados para acompañar su demanda de recibir el patronato de las Indias en detrimento del rey de Castilla. ${ }^{39}$ Los teólogos de la causa afirmaban que el procedimiento era ilícito y el condenado Baltasar de Aguilar precisaba que, "en los dos años después de la insurrección, será obtenida una gracia pontifical que dé la absolución por las cosas de México". ${ }^{40} \mathrm{La}$ soberanía del futuro príncipe sería reconocida en todo el país. El deán del cabildo de México iría clandestinamente a Italia para recibir allí del pontífice la investidura del nuevo reino.

Según los testigos del complot de Cortés, los conspiradores esperaban la llegada de una monarquía del mérito mantenida por la futura nobleza de las ciudades y las élites indianas. Su cifra total se había duplicado con una nueva aristocracia titulada a la que accederían los hombres honorables más ilustres. La toma de México no podía bastar para someter a Nueva España. Con una tropa de gentes armadas experimentadas, don Luis Cortés ocuparía San Juan de Ulloa y pretendería la flota que allí arribaba. Otro capitán debía ser enviado rápidamente a Guatemala. Por último, don Martín conservaría las minas de Zacatecas, que ocuparía con varios centenares de hombres.

Los rebeldes abogaban por una política indiana conservadora. Si la corona protegía paulatinamente a los indios, sus administradores no tardarían en descuidar su doctrina católica y en aumentar la carga tributaria en su propio beneficio. Los recursos de la Hacienda, así como los vertidos en las comunidades aldeanas, se encontraban bastante menguados. Los rebeldes ofrecían también estos discursos a los indígenas.

39 AGI, Patronato, 205, R. 1, fol. 222v.

40 AHN, DIDC, 39, N. 1, fol. 11. 
Por esos motivos, los jueces sospechaban que Diego Olarte, un franciscano de Texcoco, había agrupado a los indios de Tlaxcala en el complot de Cortés con la idea de decantar las filas de la insurrección. De hecho, varios de sus caciques fueron llevados ante el rey de Castilla sin que pudieran ser escuchados. Sin embargo, "y si los Indios se alborotaren pacificar se han con moderarles los tributos quitándoles algo de lo que ahora pagan y así todo se sosegará". Representantes indios y españoles sufrían de la misma manera la tiranía del rey, que quería imponer tributo a los caciques y privarlos de su parte de ganancias generadas en las encomiendas.

El gobierno nacido de la insurrección se encargaría del destino económico y comercial de la colonia. El destino de los comerciantes en la futura corona exigía una atención particular; por eso, al ser solicitados para equipar a los soldados, se beneficiaron ampliamente de los frutos de la revuelta. La novedad vendría de la política económica de libre cambio practicada con los aliados ingleses, los holandeses y los franceses, la cual compensaría la ruptura con España. Lo cierto es que la tierra daba suficientes frutos para alimentar a todos los españoles si el rey de Castilla no les privaba de sus recursos. Las licencias de comercio expedidas en ese sentido constituirían la contrapartida del apoyo de los aliados a la insurrección y, a la vez, una promesa dirigida a los comerciantes españoles de las Indias, que podrían así importar productos a mejor precio. Vino, telas y paños vendrían a partir de entonces de Francia, Inglaterra y Flandes. La libertad de comercio y la reducción de los circuitos de intercambios garantizarían el mantenimiento de los precios bajos. La política de alianza de la futura corona se unía a esta evidencia. Para los jueces de México y para los del Consejo de Indias, 
cada uno de los puntos de esta línea política agravaba aún más el delito de los detenidos del complot de Cortés.

Es dudoso que aquellos proyectos, descubiertos a trozos por los testigos, hayan constituido un auténtico programa insurreccional. En cambio, sus componentes, repetidos hasta la saciedad, se encontraban sistemáticamente en todos los grandes procesos políticos de la época. Estos componentes revelan la aparición de una incipiente conciencia política criolla, convencida de la necesidad de traducir las diferencias entre las Indias y la Península mediante formas diversas de autonomía de las monarquías indianas. La difusión de aquellas ideas fue enormemente facilitada por la circulación de los individuos en el propio mundo americano. Las élites de Cuzco, Lima y Quito estaban muy atentas a lo que pasaba en México, Puebla y Guatemala. Las carestías de la administración peninsular reforzaban la credibilidad de las afirmaciones de los rebeles que prometían siempre ayudas a los más pobres y a los emigrantes llegados recientemente. A pesar del alcance de la popularidad de algunos movimientos insurreccionales, como el de Francisco Hernández de Girón, la corona de Castilla ganó finalmente sus tres batallas: la de las armas, la de la Hacienda y la de la memoria. La gran novedad fue, en cambio, el recurrir a la administración judicial a un lado y otro del Atlántico, para perseguir a todos los insurgentes de forma duradera. Así, la judicialización del ámbito político se convirtió en el arma principal del doblegamiento social de las Indias de Castilla.

Traducción de Manuela Águeda García Garrido 


\section{SIGLAS Y REFERENCIAS}

AGI Archivo General de India, Sevilla.

AHN Archivo Histórico Nacional, Madrid.

DIDC Serie Documentos de Indias, Diversos-Colecciones del Archivo Histórico Nacional, Madrid.

BARnadas, Josep María

Charcas, 1535-1565. Orígenes históricos de una sociedad colonial, La Paz, Casilla, 1973.

Barral Gómez, Ángel

Rebeliones indigenas en la América española, Madrid, Mapfre, 1992.

Bataillon, Marcel

“Interés hispánico del movimiento pizarrista (1544-1548)”, en Pierce y Jones, 1964, pp. 47-56.

Brendecke, Arndt

Imperium und Empirie. Funktionen des Wissens in der Spanischen Kolonialherrschaft, Colonia, Böhlau, 2009.

Byrd Simpson, Lesley

Many Mexicos, Berkeley, University of California Press, 1941.

Calvete de Estrella, Juan

Rebelión de Pizarro en el Perú y vida de D. Pedro Gasca, edición de A. Paz y Meliá Madrid, M. Tello, 1889.

Clavero Salvador, Bartolomé

Historia del derecho: derecho común, Salamanca, Universidad de Salamanca, 1994.

Duviols, Pierre

La Lutte contre les religions autochtones du Pérou colonial. 
L'extirpation de l'idolâtrie, entre 1532 et 1660, Lima, Institut Français D’Études Andines, 1971.

García Martínez, Bernardo

El Marquesado del Valle. Tres siglos de régimen señorial en Nueva España, México, El Colegio de México, 1969.

Giudicelli, Christophe

Pour une géopolitique de la guerre des Tepebuán (1616-1619). Alliances indiennes, quadrillage colonial et taxinomie etbnographique au Nord-Onest du Mexique, París, Université de la Sorbonne-Nouvelle, 2003.

Gutiérrez de Santa Clara, Pedro

Quinquenarios, o Historia de las guerras civiles del Perú, en Pérez de Tudela Bueso, 1963-1965, t. II.

Himmerich y Valencia, Robert

The Encomenderos of New Spain, 1521-1555, Austin, University of Texas Press, 1991.

Huamán Pomán de Ayala, Felipe

El primer nueva crónica y buen gobierno, Copenhague, Biblioteca Real de Dinamarca, 1615.

LOCKHART, James

The Men of Cajamarca: A Social and Biographical Study of the First Conquerors of Peru, Austin, University of Texas Press, 1972.

Lohmann Villena, Guillermo

Los regidores perpetuos del cabildo de Lima (1535-1821). Crónica y estudio de un grupo de gestión, Sevilla, Diputación Provincial de Sevilla, 1983.

Las ideas jurídico-politicas en la rebelión de Gonzalo Pizarro. La tramoya doctrinal del levantamiento contra las Leyes Nuevas en el Perú, Valladolid, Publicaciones de la Universidad de Valladolid, 1977. 
Pérez de Tudela Bueso, Juan (ed.)

Crónicas del Perú, Madrid, Atlas, 1963-1965, 5 volúmenes.

Pietschmann, Horst

El estado y su evolución al principio de la colonización española de América, traducción de Angélica Scherp, México, Fondo de Cultura Económica, 1989.

Pierce, Franck y Cyril A. Jones (dirs.)

Actas del primer Congreso internacional de hispanistas, Oxford, Dolphin Books, 1964.

Porras Barrenechea, Raúl

El cronista indio Felipe Huamán Poma de Ayala (¿15341615?), Lima, Lumen, 1948.

Powell, Philip Wayne

La guerra chichimeca (1550-1600) [1952], México, Fondo de Cultura Económica, 1984.

Puente Brunke, José de la

Encomienda y encomenderos del Perú, Sevilla, Diputación provincial de Sevilla, 1992.

SALINero, Gregorio

La trabison de Cortés. Désobéissances, procès politiques et gouvernement des Indes de Castille, seconde moitié du XVI siècle, París, Presses Universitaires de France, 2014.

Sarabia Viejo, Justina

Don Luis de Velasco. Virrey de Nueva España, 1550-1564, Sevilla, Escuela de Estudios Hispano Americanos, 1978.

SBRICCOLI, Mario

Crimen laesae maiestatis. Il problema del reato politico alla soglie della scienza penalistica moderna, Milán, Giuffrè, 1974. 
Sherman, William L.

"Indian Slavery and the Cerrato Reforms", en The Hispanic American Historical Review, 51 (1971).

Thomas, Yan

"L’institution de la Majesté", en Revue de synthèse, 3-4 (1991), pp. 331-386.

VARón Gabai, Rafael

La ilusión del poder. Apogeo y decadencia de los Pizarro en la conquista del Perú, Lima, Institut Français d'Études Andines, 1997.

Zavala, José Manuel

Les Indiens Mapuche du Chili. Dynamiques inter-ethniques et stratégies de résistance, XVIII siècle, París, L'Harmattan, 2000.

Zavala, Silvio

Los esclavos indios en Nueva España, México, Colegio Nacional, 1981. 